\title{
OS DEDOS COÇANDO POR DETRÁS DO CICLORAMA, OU O OUTRO LADO HOMEOSTÁTICO DO SER
}

\author{
António Barros*
}

RESUMO: Para José-Alberto Marques perante os seus 10 homeóstatos.

PALAVRAS-CHAVE: Homeóstatos. José-Alberto Marques. Poesia Experimental Portuguesa. Releitura.

*Poeta. Coimbra, Portugal. E-mail: artitude.ab@gmail.com 
Fig. 1 - "nos dedos aparando amparo até ao grito"
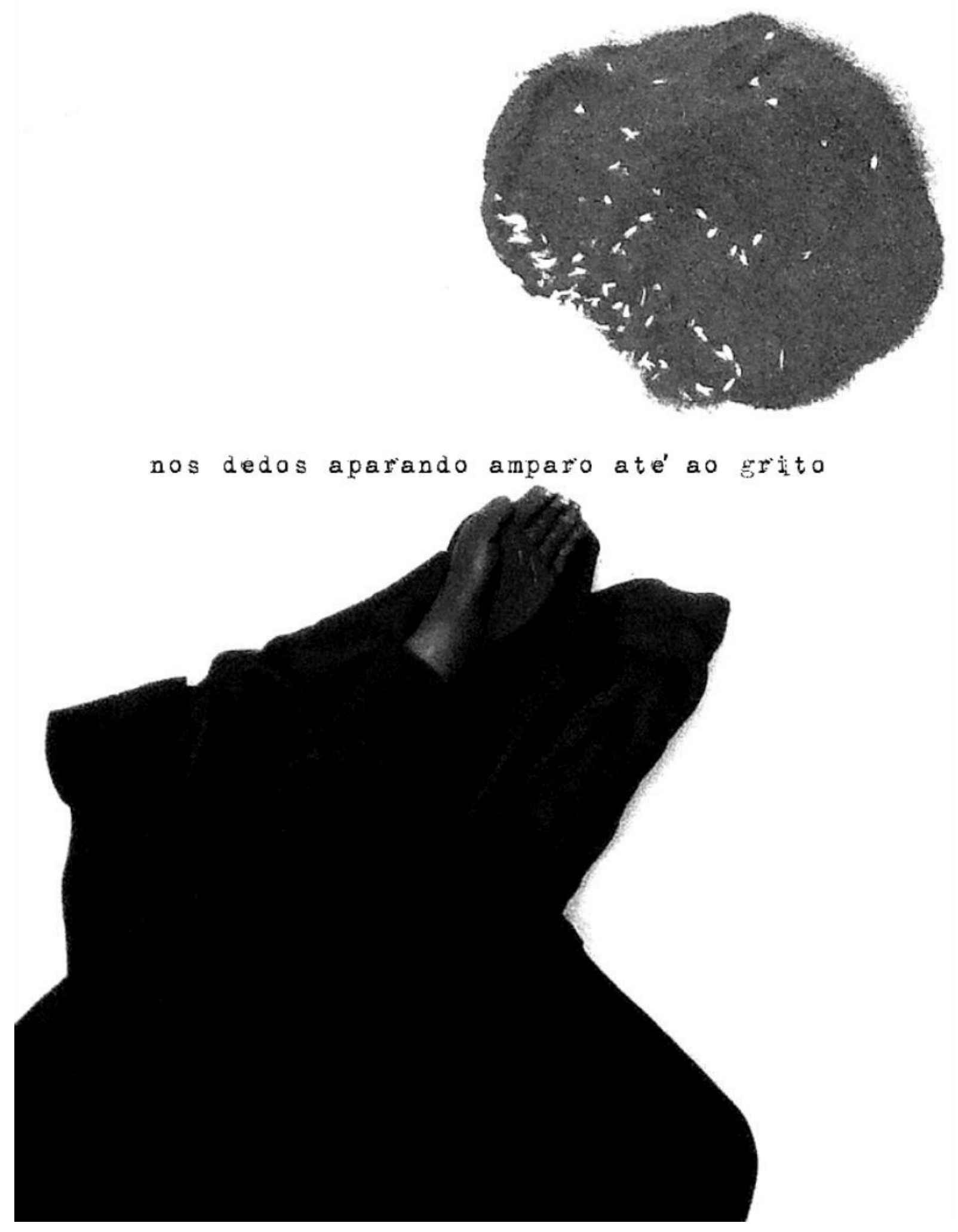

Texto Digital, Florianópolis, Santa Catarina, Brasil, v. 12, n. 1, p. 184-194, jan./jun. 2016. ISSNe: 1807-9288. 
Fig. 2 - "nos dedos raspando a faca até ao osso"

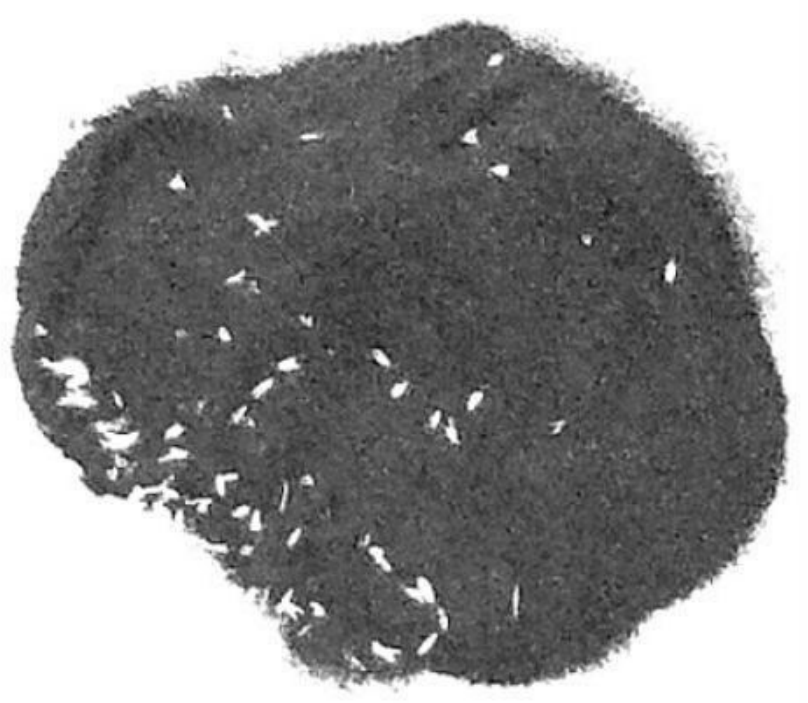

nos dedos raspando a fiea ate' a osso

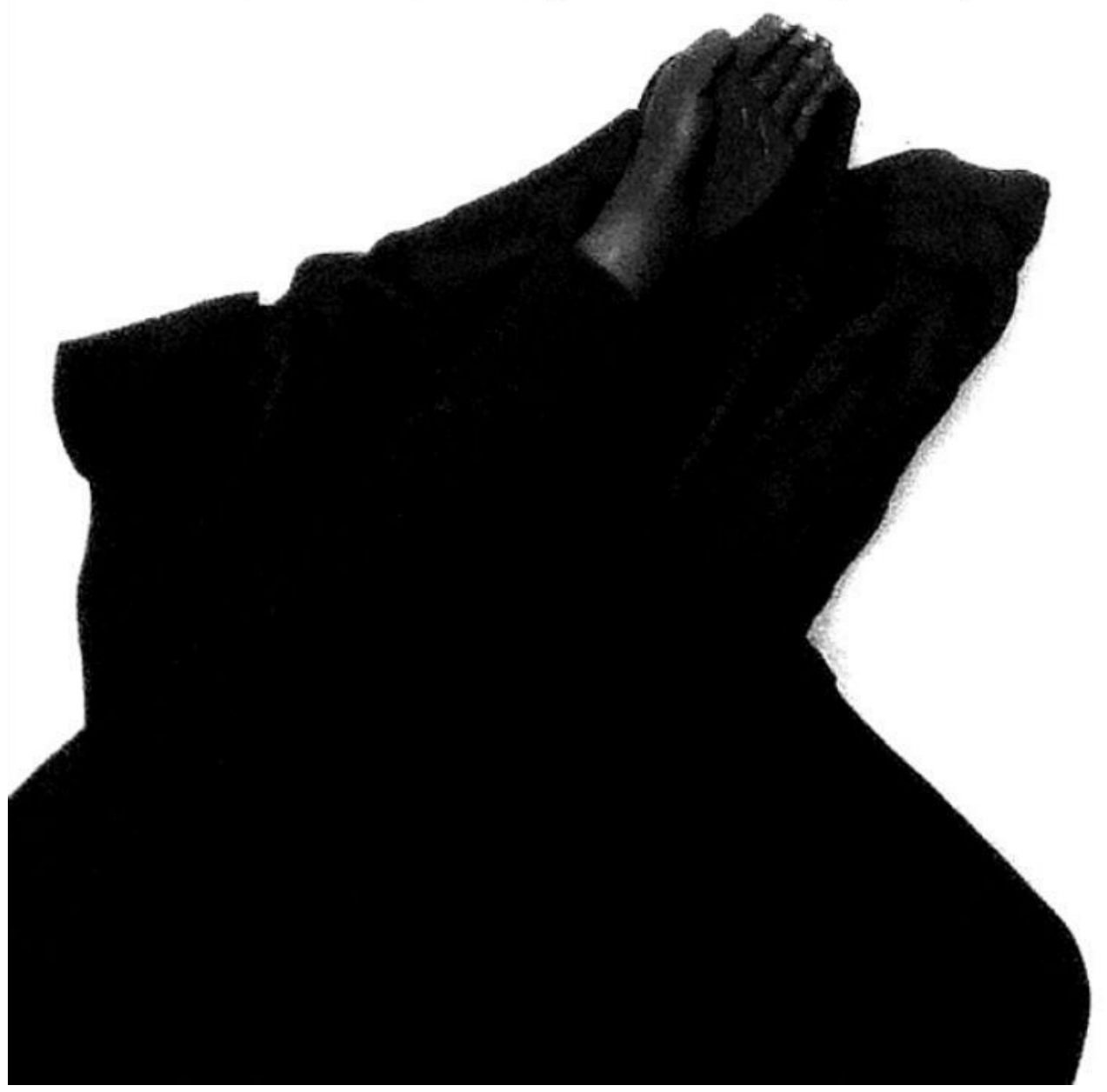

Texto Digital, Florianópolis, Santa Catarina, Brasil, v. 12, n. 1, p. 184-194, jan./jun. 2016. ISSNe: 1807-9288. 
Fig. 3 - "nos dedos sofridos a mão aberta conVida"

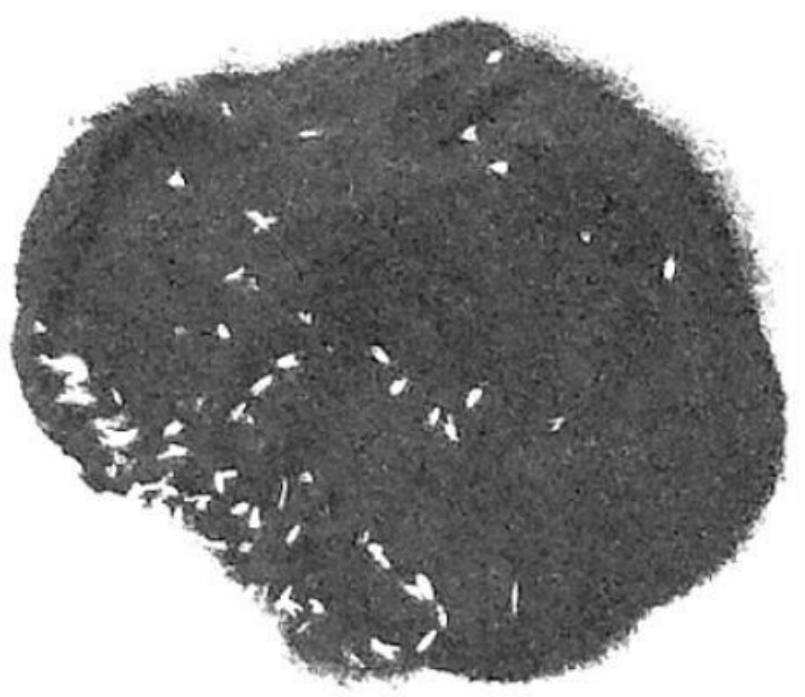

nas dedas safrílas a māa aberta sonVida

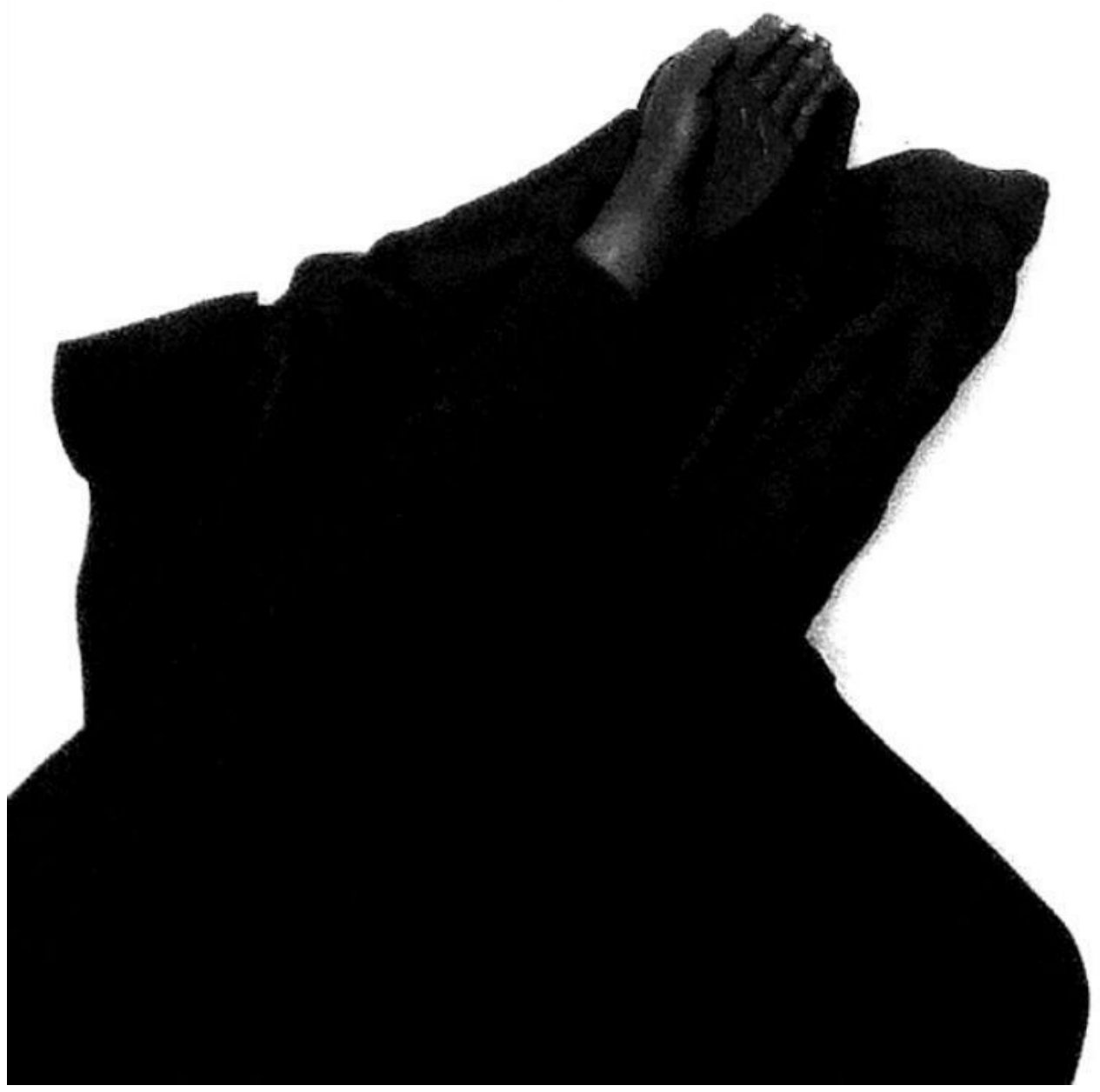

Texto Digital, Florianópolis, Santa Catarina, Brasil, v. 12, n. 1, p. 184-194, jan./jun. 2016. ISSNe: 1807-9288. 
Fig. 4 - "nos dedos explodidos grito quanto amo e posso"

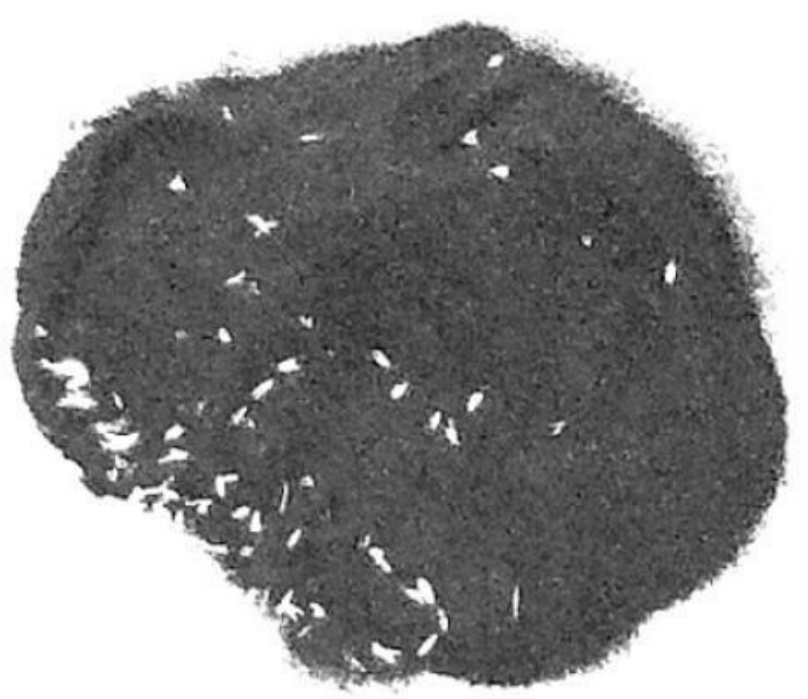

nos dedas explodidos grito quanto amo e posso

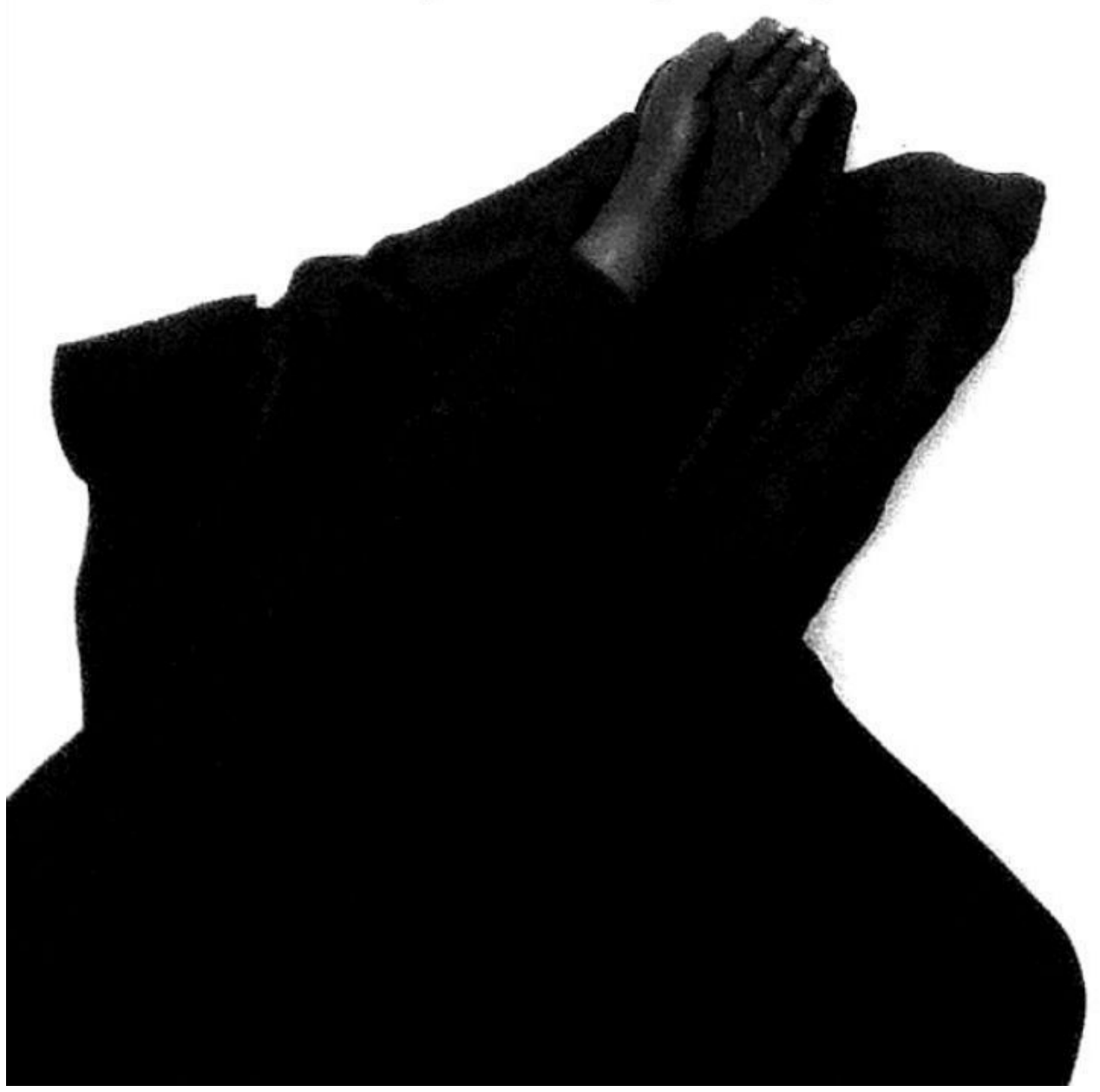

Texto Digital, Florianópolis, Santa Catarina, Brasil, v. 12, n. 1, p. 184-194, jan./jun. 2016. ISSNe: 1807-9288. 
Fig. 5 - "nos dedos já secos faltou o sangue"
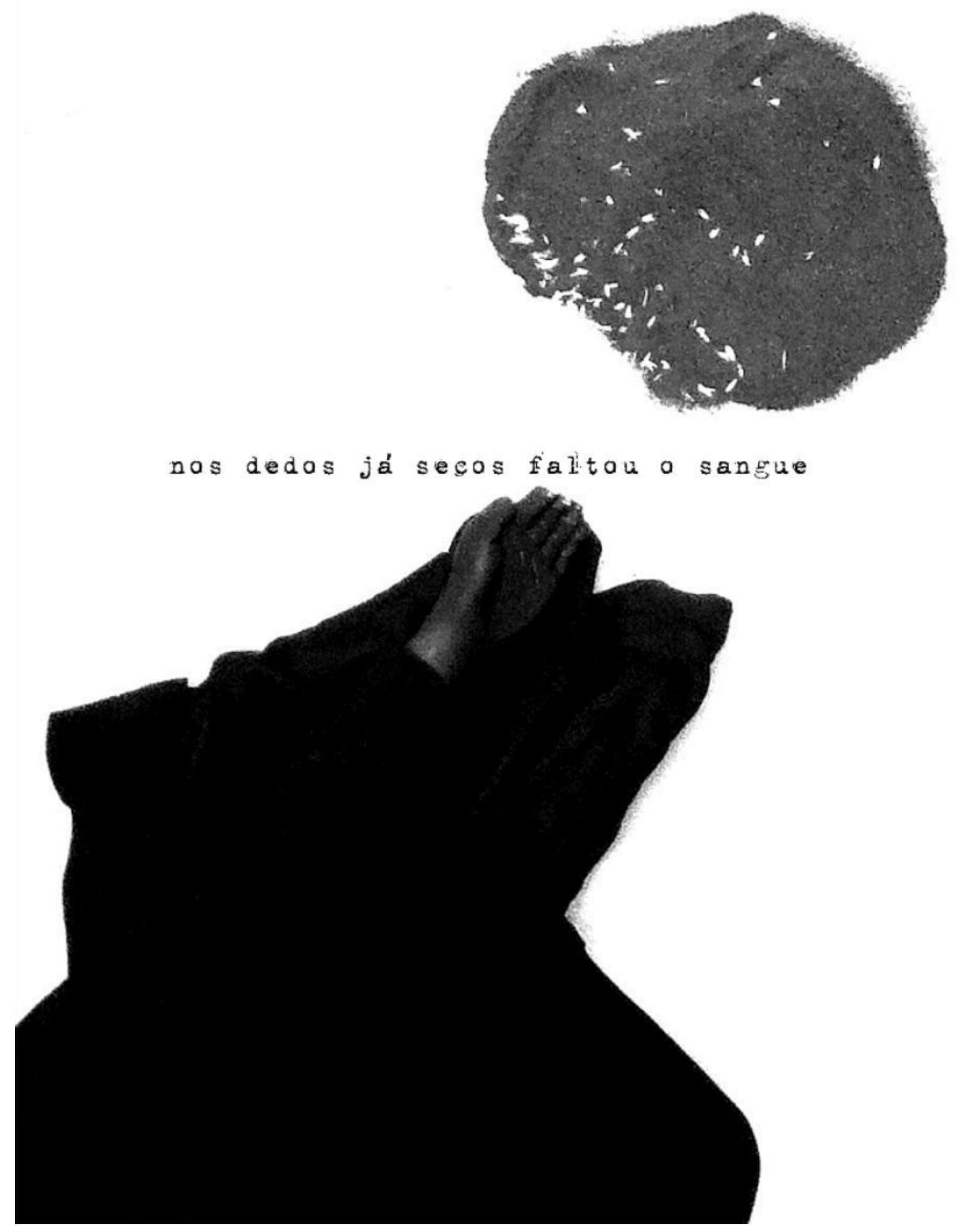

Texto Digital, Florianópolis, Santa Catarina, Brasil, v. 12, n. 1, p. 184-194, jan./jun. 2016. ISSNe: 1807-9288. 
Fig. 6 - "nos dedos sem pontas mordidos pela serpente"

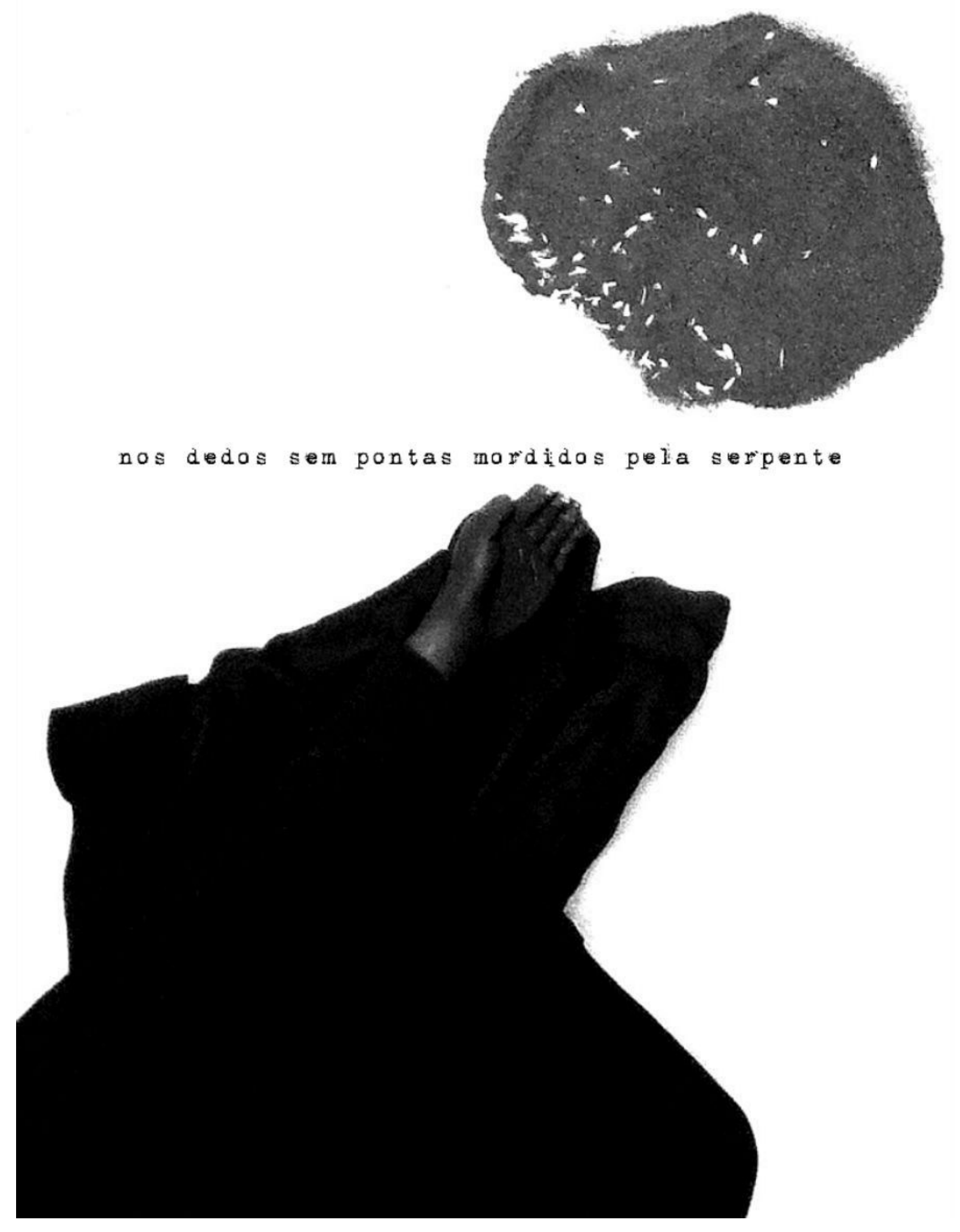

Texto Digital, Florianópolis, Santa Catarina, Brasil, v. 12, n. 1, p. 184-194, jan.jjun. 2016. ISSNe: 1807-9288. 
Fig. 7 - "nos dedos em x afastando o azar"
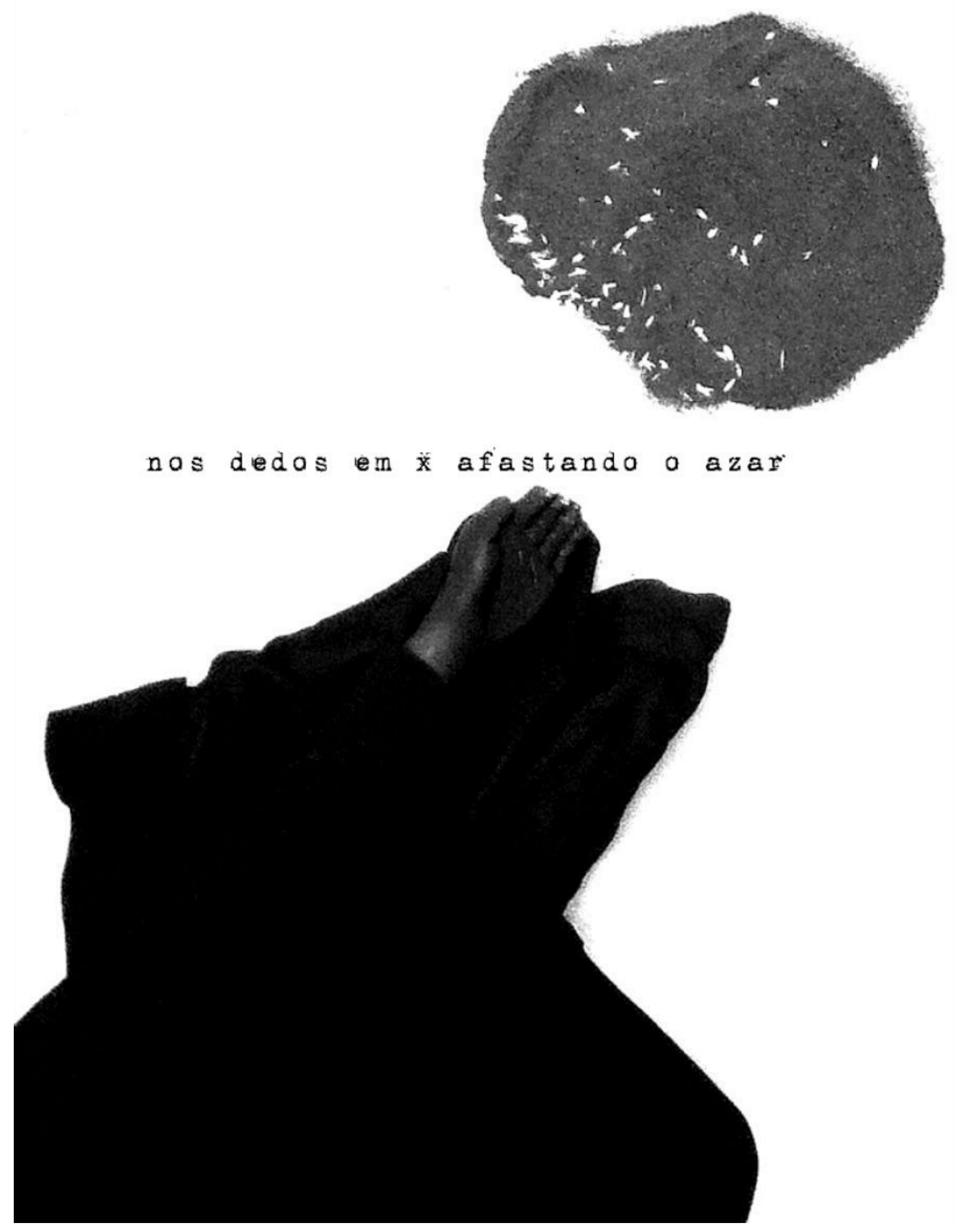

Texto Digital, Florianópolis, Santa Catarina, Brasil, v. 12, n. 1, p. 184-194, jan./jun. 2016. ISSNe: 1807-9288. 
Fig. 8 - "nos dedos mesmo cortados sempre um querer válido"

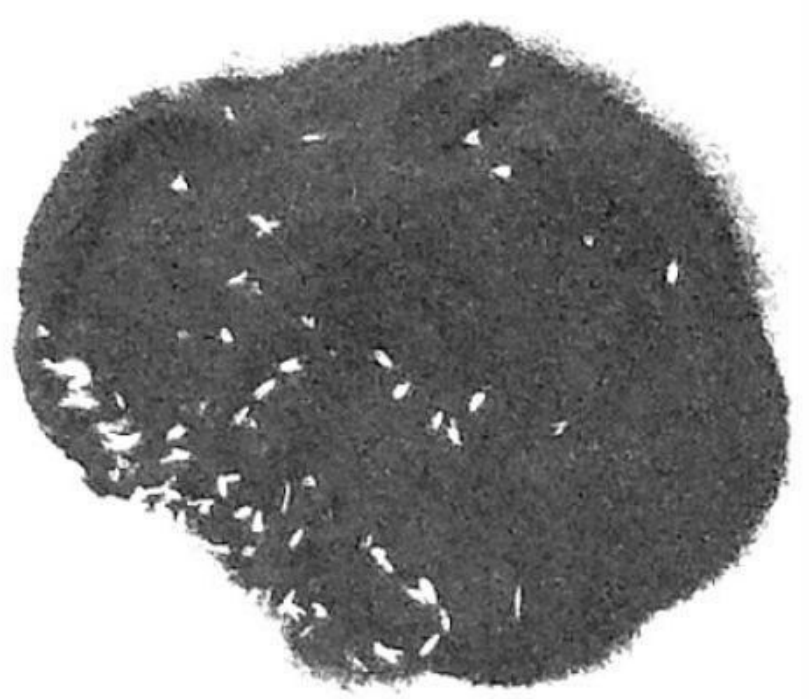

nos dedas mesmo sortados sempre um querer válido

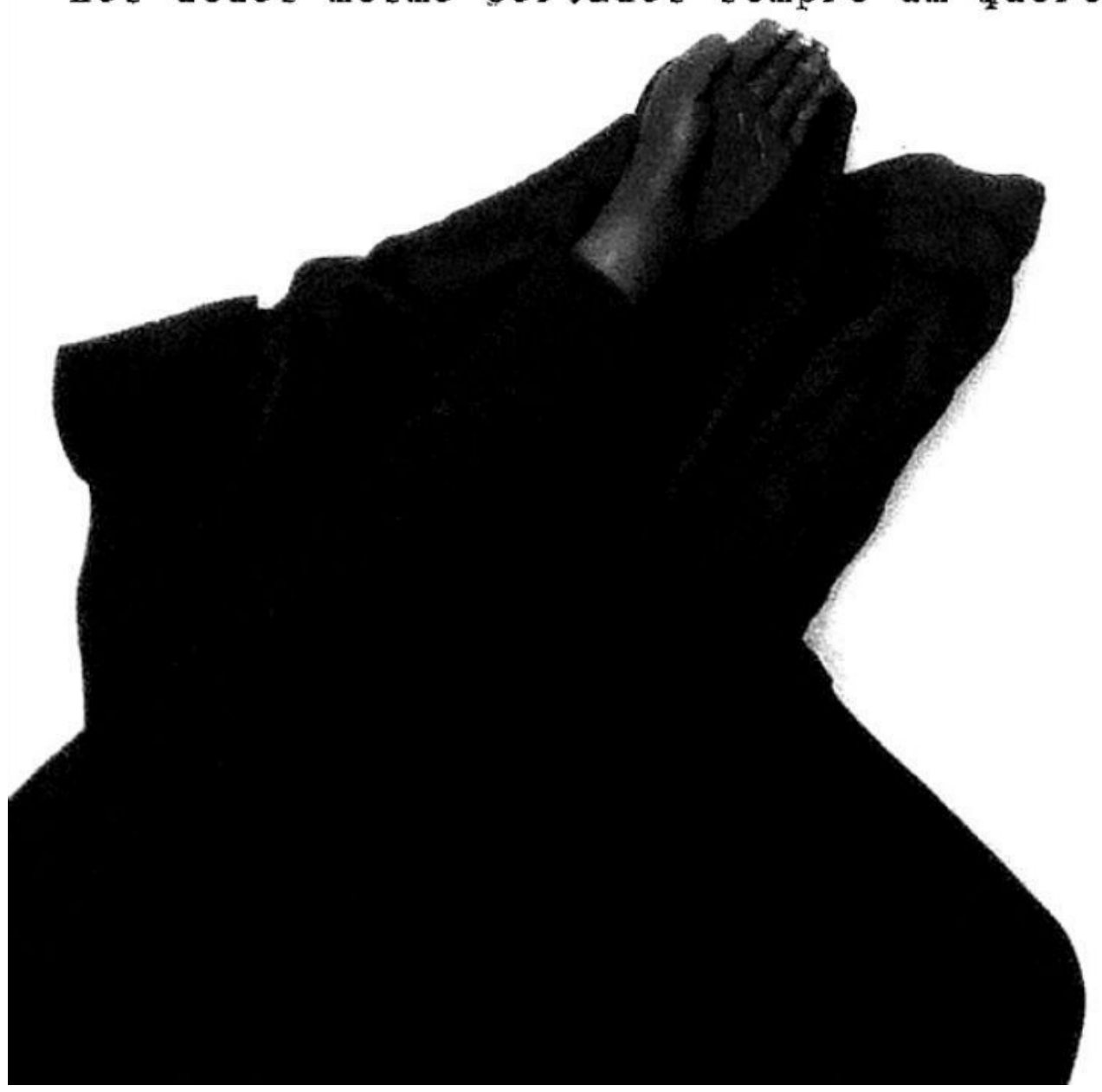

Texto Digital, Florianópolis, Santa Catarina, Brasil, v. 12, n. 1, p. 184-194, jan.jjun. 2016. ISSNe: 1807-9288. 
Fig. 9 - "nos dedos coutos para fazer passar o vento"
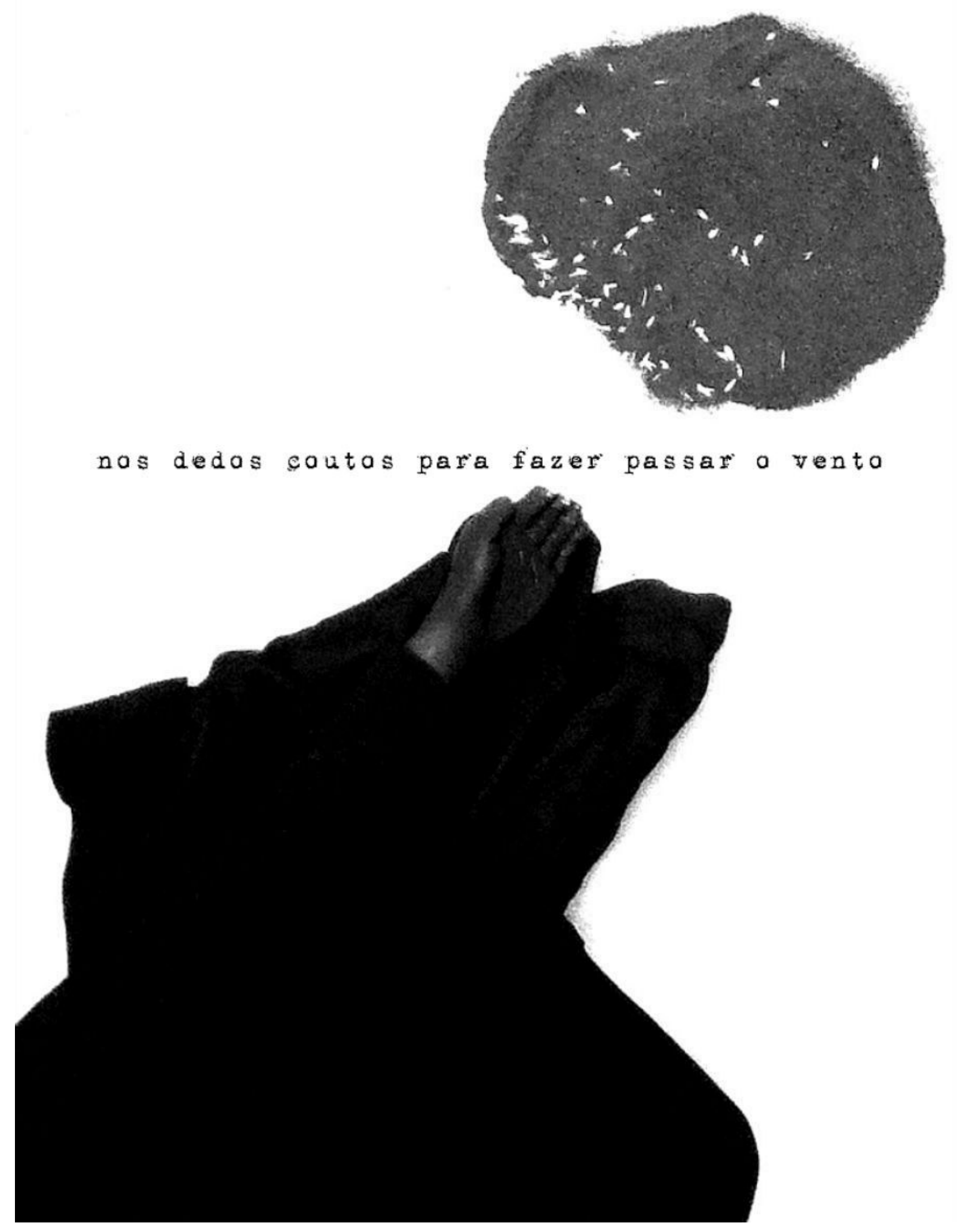

Texto Digital, Florianópolis, Santa Catarina, Brasil, v. 12, n. 1, p. 184-194, jan./jun. 2016. ISSNe: 1807-9288. 
Fig. 10 - "nos dedos esquecidos o ser restou-se em pedra"

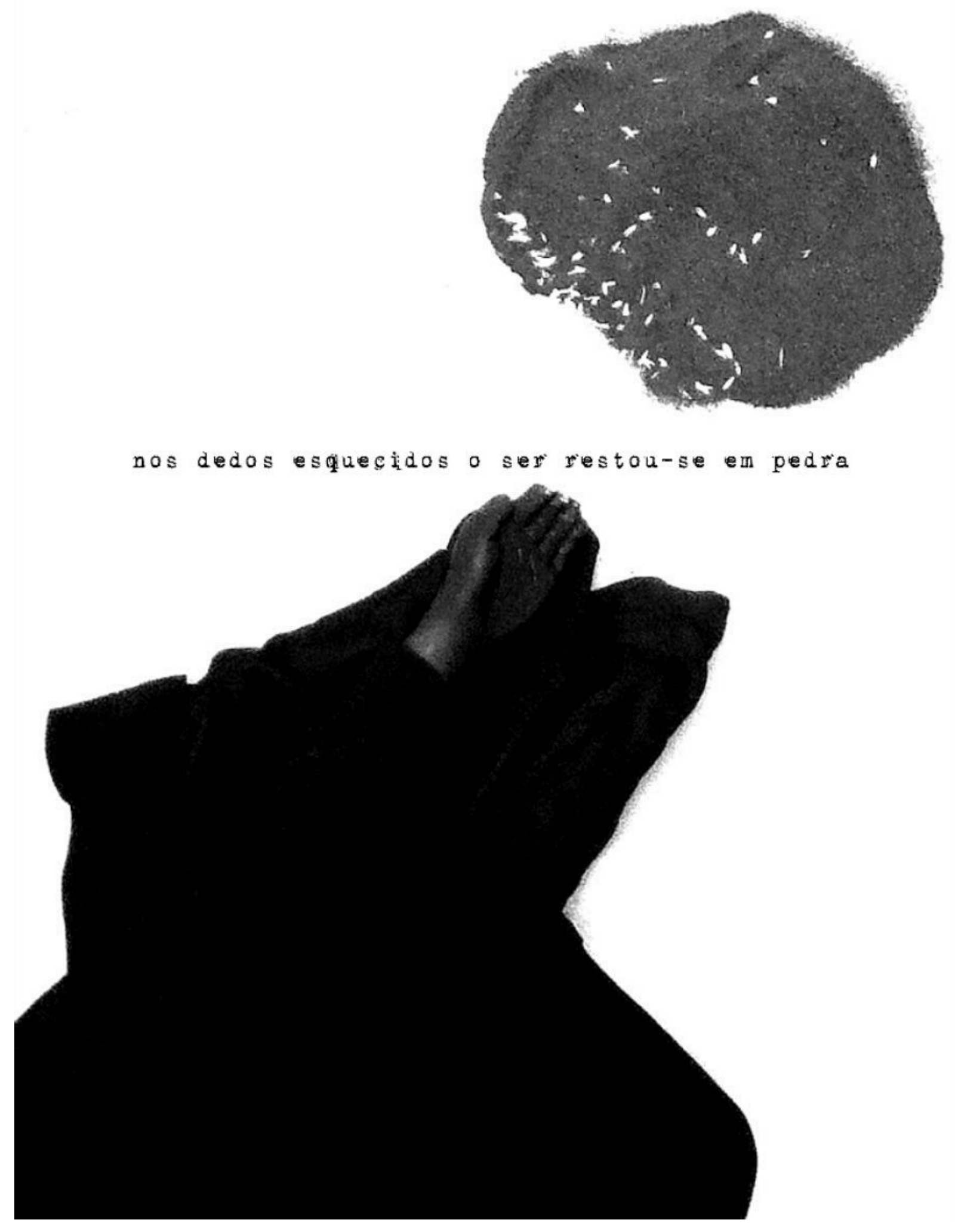

Texto Digital, Florianópolis, Santa Catarina, Brasil, v. 12, n. 1, p. 184-194, jan./jun. 2016. ISSNe: 1807-9288. 